\title{
BIOGEOCHEMICAL PRoCESSES IN AMAZON SHELF SEDIMENTS
}

\author{
By Robert C. Aller, Josephine Y. Aller, \\ Neal E. Blair, James E. Mackin, \\ Peter D. Rude, Ian Stupakoff, \\ Sambasiva Patchineelam, Susan E. Boehme \\ and Bastiaan Knoppers
}

\section{$\mathrm{E}$} ACH YEAR the Amazon River delivers approximately 1 billion metric tons of sediment to the equatorial Atlantic (Meade et al., 1985). A portion of this debris is highly weathered and contains abundant reactive $\mathrm{Fe}, \mathrm{Mn}, \mathrm{Al}$, and $\mathrm{Si}$ oxides. The associated terrestrial organic matter is biologically refractory (Hedges et al., 1986). Upon entering the Amazon Shelf region, particles are exposed to seawater brine, mixed with labile planktonic organic matter, and incorporated into the seabed where a variety of geochemical reactions take place. Major research efforts within the AmasSeds Project include elucidating the types and rates of these diagenetic reactions (particularly those associated with the decomposition of organic matter), their governing factors, and their influence on the properties of overlying water and preserved deposits.

Modern views of early diagenetic processes in shallow marine sediments have largely derived from studies of temperate estuaries and shelves, particularly along the coasts of North America and Europe. In these environments, sedimentary organic matter is decomposed through the general sequential series of biogeochemical oxidants $\left(\mathrm{O}_{2}\right.$, $\mathrm{NO}_{3}^{-}, \mathrm{Mn}, \mathrm{Fe}, \mathrm{SO}_{4}^{-}, \mathrm{CO}_{2}$ ), although reactions are typically dominated over large vertical intervals by sulfate reduction or methanogenesis. Oxygen is often relegated to a largely indirect role as an oxidant of anaerobic metabolites. Other potential oxidants of organic matter such as $\mathrm{NO}_{3}^{-}, \mathrm{Mn}$ and Fe oxides, are of minor importance (Jorgensen, 1982; Chanton and Martens, 1987; Mackin and Swider, 1989). The chemical properties of sediments and patterns of authigenic mineral formation in deposits reflect these reaction paths, as well as diagenetic transport regimes strongly in-

R.C. Aller, J.Y. Aller, J.E. Mackin, P.D. Rude, I. Stupakoff, Marine Sciences Research Center, State University of New York, Stony Brook, NY 11794 USA. N.E. Blair, S.E. Boehme, Marine, Earth, and Atmospheric Sciences, North Carolina State University, Raleigh, NC 27695 USA. S. Patchineelam, B. Knoppers, Departamento de Geoquimica, Universidade Federal Fluminense, 24210, Niteroi RJ, Brasil. fluenced by the bioturbation activities of benthic organisms (Berner, 1980). In contrast, early studies of Amazon Shelf sediments demonstrated extensive zones of suboxic reactions associated with $\mathrm{Fe}, \mathrm{Mn}$ reduction and oxidation cycles, and little evidence of macrobenthic activity (Aller et al., 1986; Aller and Aller, 1986). Unlike other shelf deposits of similar organic content $(0.6 \pm 0.1 \%$ C), sulfate depletion is limited, dissolved sulfide is undetectable, and sulfide minerals are minor in the upper few meters (total reduced $\mathrm{S}$ is typically $<0.1 \%$ ). High concentrations of dissolved $\mathrm{Fe}^{++}$ and $\mathrm{Mn}^{++}$in pore water $(0.1-1 \mathrm{mM})$ are found throughout the upper 0.5-2 m of Amazon deposits compared with vertical intervals $0.01-0.05-\mathrm{m}$ thick in many shelves. These suboxic zones extend across the Amazon Shelf for $\sim 100 \mathrm{~km}$, encompassing an area of at least $40,000 \mathrm{~km}^{2}$ off Brazil alone. Because $\mathrm{Fe}$ and $\mathrm{Mn}$ oxides and their reduction products are carrier phases for numerous minor and trace elements, their redox cycling can critically influence oceanic chemistry. The input of highly weathered debris (ferricrete, laterite) and massive physical mobility/reworking of sediments are apparently critical factors determining these patterns.

Seabed geochemistry and associated benthic biological studies during the AmasSeds project (see introductory article by Nittrouer et al. this issue a) are designed to document large-scale diagenetic processes on the Amazon Shelf, to exploit unique biogeochemical and physical features for study of modern elemental cycles, and to provide insights into ancient sedimentary environments. Specifically, the objectives are to: (1) document seasonal variation in geochemical properties and reaction rates related to carbon and metal cycling in the upper 1-2 $\mathrm{m}$ of the seabed; (2) elucidate the major physical, chemical, and biological factors controlling diagenetic and benthic community patterns; (3) determine the source and reactivity of organic carbon driving seabed reactions; (4) examine the formation of authigenic minerals including Fe carbonates, phosphates, sulfides, and silicates; (5) estimate the impact of seabed dia-
Modern views of

early diagenetic processes in shallow marine sediments have largely derived from studies of temperate estuaries and

shelves... 
genetic reactions on water-column properties and material export off the shelf; (6) evaluate the effect of biological activities on sediment characteristics; and (7) examine the potential translation of modern diagenetic processes unique to the Amazon Shelf into the geologic record for this class of environments. Particular attention has been given to interpreting the Amazon Shelf as an analogue of ancient shallow environments which produced sediments rich in authigenic Fe minerals.

\section{Sampling Approach and Methods}

Sampling sites on the shelf were chosen to promote integration between AmasSeds research groups, thereby constraining interpretations and maximizing implications of measurements. Seasonal studies of diagenesis and sediment-water interactions are continuing at three sites along two shore-perpendicular transects: 1) off the river mouth (RMT), and 2) a more northern OpenShelf Transect (OST) (Fig. 1). In addition, a transect (ST) south of RMT has been sampled for sediment-water solute exchange and benthic communities; and, a transect (NT) north of OST was sampled for benthos. These transects encompass a variety of major sedimentation and biological regimes. Sampling to date has taken place in August, February, and May during periods typical of descending, ascending, and peak flow periods of the Amazon River. These months also include

\section{decomposition}

rates... periods of varying wind stress and influence of the North Brazilian Coastal Current (Nittrouer et al., this issue a; Geyer $e t$ al., this issue). A future cruise during minimum river flow (October) will complete the temporal sampling plan.

Geochemical and benthic biological sampling along the two major transects have included collection of: one $0.25-\mathrm{m}^{2}$ box core, two $0.1-\mathrm{m}^{2}$ box cores, and one or two $\sim 3 \mathrm{~m}$ long kasten cores at each site. Plankton samples also were obtained to determine availability of colonizing benthic species. Subcores from the $0.25-\mathrm{m}^{2}$ box core were incubated aboard ship for $\mathrm{O}_{2}$ nutrient, and dissolved $\mathrm{Fe}$ and $\mathrm{Mn}$ diffusive flux estimates. In situ incubations using benthic landers are precluded by physical conditions on the shelf. Box cores and kasten cores were sampled over $\sim 1-5 \mathrm{~cm}$ and 10 $\mathrm{cm}$ depth intervals, respectively, and pore waters were separated under anoxic conditions. Nutrients and $\mathrm{CO}_{2}$ were analyzed aboard ship. Sediment incubation experiments were used to estimate selected reaction rates for $\mathrm{Mn}, \mathrm{Fe}, \mathrm{SO}_{4}^{\overline{4}}$ reduction, and for $\mathrm{CO}_{2}, \mathrm{NH}_{4}^{+}$, and $\mathrm{HPO}_{4}^{-}$production as a function of depth in the cores. These measurements help constrain interpretations of pore-water distributions and transport processes. Experiments were set-up to determine the composition of authigenic mineral precipitates and are in progress. Pore-water samples were stored for $\mathrm{C}$ isotopic analyses. Core samples have been archived and frozen for solid-phase analyses, including organic geochemical and authigenic-mineral studies.

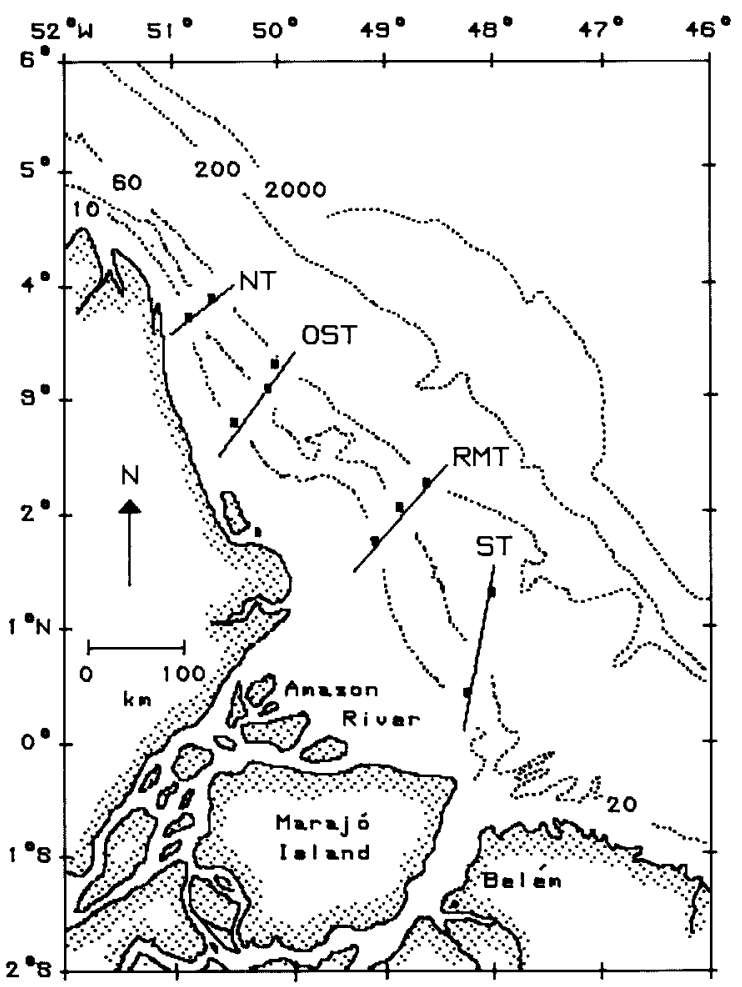

Fig. 1: Location of major transects (OST, RMT, $S T, N T)$ and sampling stations for diagenetic and benthic biological studies. Benthos also have been sampled at additional stations across the shelf. On any given transect, stations are numbered 1, 2, ..., inshore to offshore.

\section{Oxidation-Reduction Reaction Rates and Balances in the Seabed}

One common measure of decomposition rate and benthic metabolism is the flux of $\mathrm{O}_{2}$ to the seafloor. If there is little storage of reduced products of decomposition in a deposit, $\mathrm{O}_{2}$ flux can correspond closely to total $\mathrm{C}$ oxidation. The redox reactivity of Amazon bottom sediments, as measured by $\mathrm{O}_{2}$ diffusive uptake, is relatively uniform and generally comparable to other, much colder temperate shelves. The yearly average of $18 \mathrm{sam}$ ples is $1.1 .8 \pm 3.8 \mathrm{mmol} \mathrm{m}^{-2} \mathrm{~d}^{-1}$, with only a hint of seasonal variation (May: $10.5 \pm 2.8$; Aug: 13.2 \pm 4.3 ) (Fig. 2). Oxygen measured in sediments by use of microelectrodes, is absent below 1-4 mm at all sites. This agrees with penetration depths estimated from a 1-dimensional diffusion model, the measured $\mathrm{O}_{2}$ flux, and bottom-water oxygen concentrations. The average ratio of diffusive fluxes estimated from pore-water concentration gradients and of directly measured (incubation) $\mathrm{O}_{2}$ fluxes is $1.07 \pm 0.19(\mathrm{~N}=6)$, also in excellent agreement.

An additional, more general measure of total remineralization is the production of $\mathrm{CO}_{2}$. Directly measured production rates of total $\mathrm{CO}_{2}$ in the upper $1-1.5 \mathrm{~m}$ of sediment demonstrate that there is no dramatic spatial variation in decomposition rates within the sampled region (Fig. 3). 


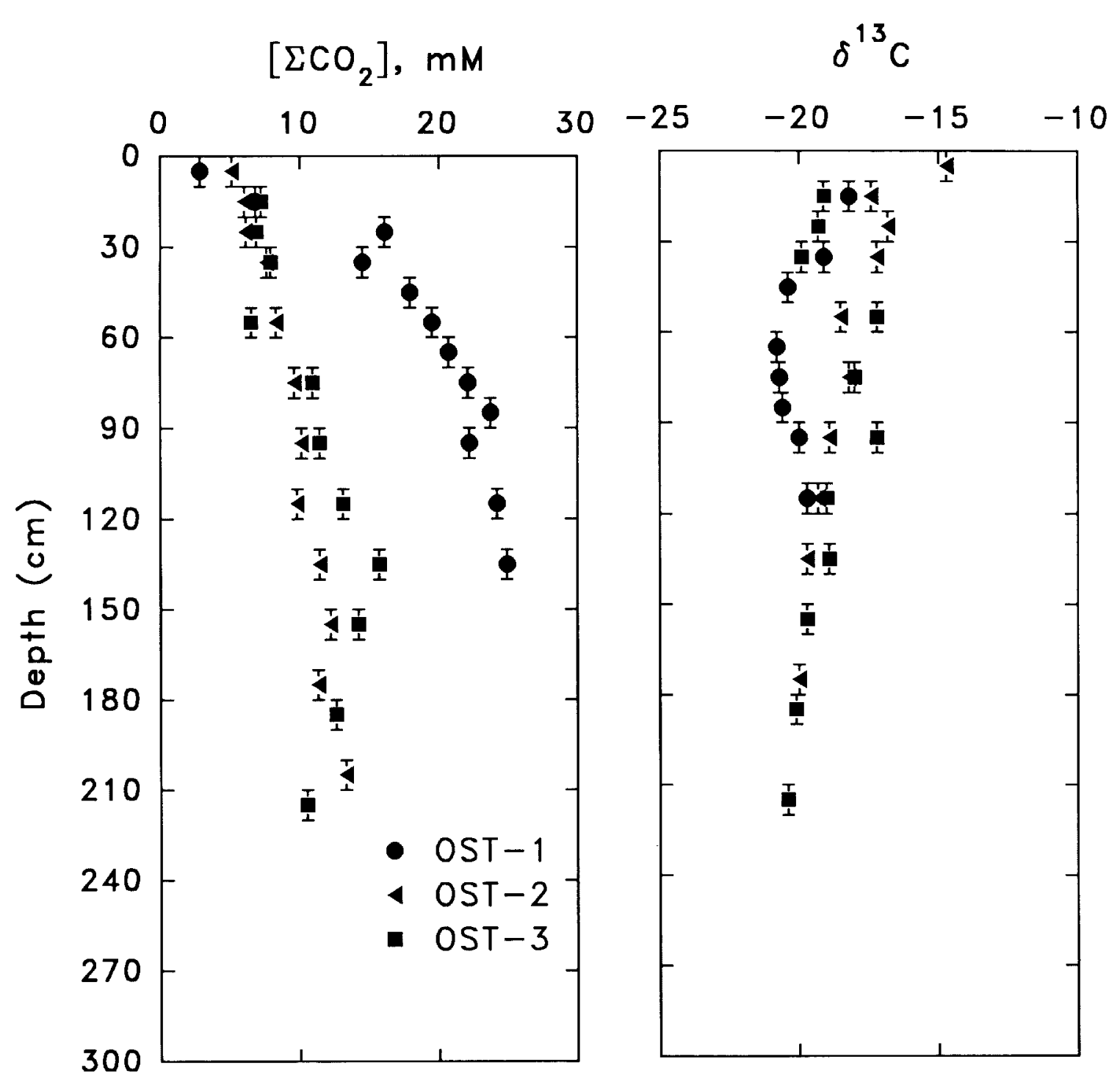

Fig. 4: Total $\mathrm{CO}_{2}$ (mmoles/liter pore water) and corresponding isotopic composition at stations along OST during May 1990.

In some locations, dramatic seasonal variability in solute profiles is observed ... tions ( $<5 \mathrm{mM}$ ) and somewhat variable $\delta^{13} \mathrm{C}$ values over the upper $1.5 \mathrm{~m}$ along RMT are consistent with frequent reworking of the seabed (see: Kineke et al., this issue; Nittrouer et al., this issue b). Preliminary modeling suggests that in some cases pore-water solute profiles over the upper $\sim 1 \mathrm{~m}$ are only about 1-2 months old due to physical disturbance or extensive biological irrigation. In some locations, dramatic seasonal variability in solute profiles also is observed, with lowest concentrations generally found during ascending river flow (Fig. 5). Thalassinid shrimp (Callianassa sp. and Upogebia sp.) are abundant at the innermost stations of RMT and may be at least partly responsible for the apparent, massive sediment-water exchange. Deep burrowing sipunculids, brittle stars (ophiuroids), and gobiid fish are also present at these stations. Solute exchange is apparently less extensive along OST, but rapid transport takes place in at least the upper $20-60 \mathrm{~cm}$, due in some instances to physically mobile fluid-mud layers.
DIC reaches $>20 \mathrm{mM}$ at OST stations and experimental incubations indicate that authigenic carbonate precipitation occurs in this region.

\section{Benthic Communities and Bioturbation Potential}

The benthic community distributions mirror the physical regime and provide insight into diagenetic transport processes and timescales of physical disturbance within deposits. There are marked increases from inshore to offshore and from north to south in macro- and meiofaunal abundances, species richness, and functional group diversities (Fig. 6). Animals between 0.5 to $1 \mathrm{~mm}$ in size, dominate the bottom community. As in most sedimentary deposits, highest abundances occur near the sediment-water interface and decrease with depth in the deposit. Polychaete worms, dominate the fauna and include surface deposit feeders such as early colonizing spionids, as well as deep deposit-feeding species. Other bur- 


\section{Fe (UM)}

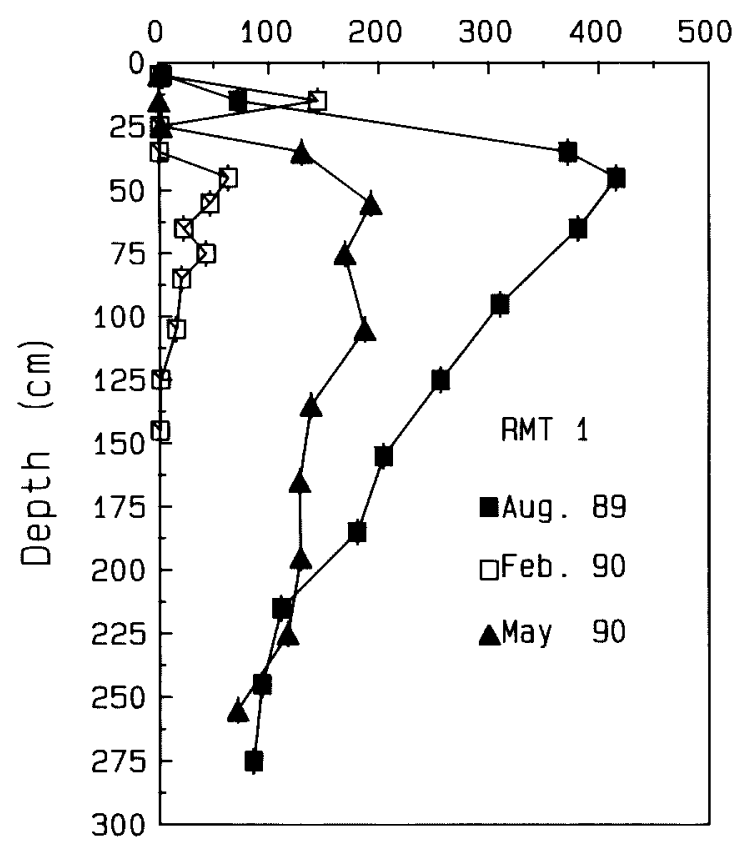

Fig. 5: Seasonal patterns of dissolved pore-water $\mathrm{Fe}$ ( $\mu$ moles/liter) at RMT-1, the most inshore station along $R M T$.

rowing organisms on the shelf include mud shrimps (thalassinids), brittle stars, lumbrinerid and cossurid polychaetes, sipunculids, and gobiid fish; which are found to depths of $25 \mathrm{~cm}$ below the surface. Large numbers of crab and shrimp larvae, as well as meiofaunal-size crustaceans (from 0.5 to $0.062 \mathrm{~mm}$ ) including copepods and cumaceans, are also found to $>25 \mathrm{~cm}$, presumably having been passively transported downward by sediment reworking.

Macrofauna reach largest size and greatest abundances during ascending river flow at all shelf stations $\left(\max =<4000 \mathrm{~m}^{2}\right.$ at ST2, depth $=47$ $\mathrm{m})$. Inshore of $15 \mathrm{~m}$, for example, abundances are 20 to 50 times greater than during descending flow. This is the time when biogeochemical properties of the sediment show evidence of recent major exchange, as mentioned previously. Model calculations indicate that burrow irrigation by the numbers and sizes of organisms present could be a significant exchange process in some locations. Also during this time, larval crustaceans of many groups are present in tens of thousands per $\mathrm{m}^{2}$. Some crustaceans (both adults and larvae) remain during peak flow periods, but have a patchy distribution. Presumably, there is a relatively constant supply of larvae and adult organisms from the south, in the near-bottom waters associated with the North Brazilian Current. These organisms may settle out of the water column when overall current speeds decrease. The lack of any evidence of sexual maturity among both adult macro- and meiofaunal organisms (except for
Upogebia sp.) suggests that very few of the organisms reproduce in these physically disturbed sediments.

\section{The Present and Past Shelf}

Seasonal variation in sediment transport/remobilization is apparently the major cause of short-term change in diagenetic and biological properties of the upper 1-2 $\mathrm{m}$ of the present shelf deposits. The relative importance of organic-matter decomposition pathways and the nature of benthic communities and sedimentation regime may have changed over longer timescales on the Amazon shelf. For example, methane concentrations $(<40 \mu \mathrm{M})$ in the upper $2-3 \mathrm{~m}$ of sediment indicate that methanogenesis is not an important mode of organic matter diagenesis in modern Amazon shelf sediments and appears to be restricted to microenvironments or narrow zones. This is in contrast to greater depths within the seabed where seismic profiling and piston-core analysis demonstrate gas-charged sediment $\left(\mathrm{Fi}^{-}\right.$ gueiredo et al., 1990). This gas is biogenic $\left(\delta^{13} \mathrm{C}\right.$ $=-84 \% 0$ ) and could result from the slow degradation of low-reactivity organic matter over a 1000-year timeframe. Alternatively, these methane deposits could have formed during a period when the flux of marine carbon to the seabed was much greater than today and perhaps sediment reworking was less intense. Sampling of deeper deposits should resolve this issue.

\section{Future Research}

This article represents a preliminary outline of some of our work on seabed diagenesis and benthic communities as part of the AmasSeds Project and of the basic research questions to be

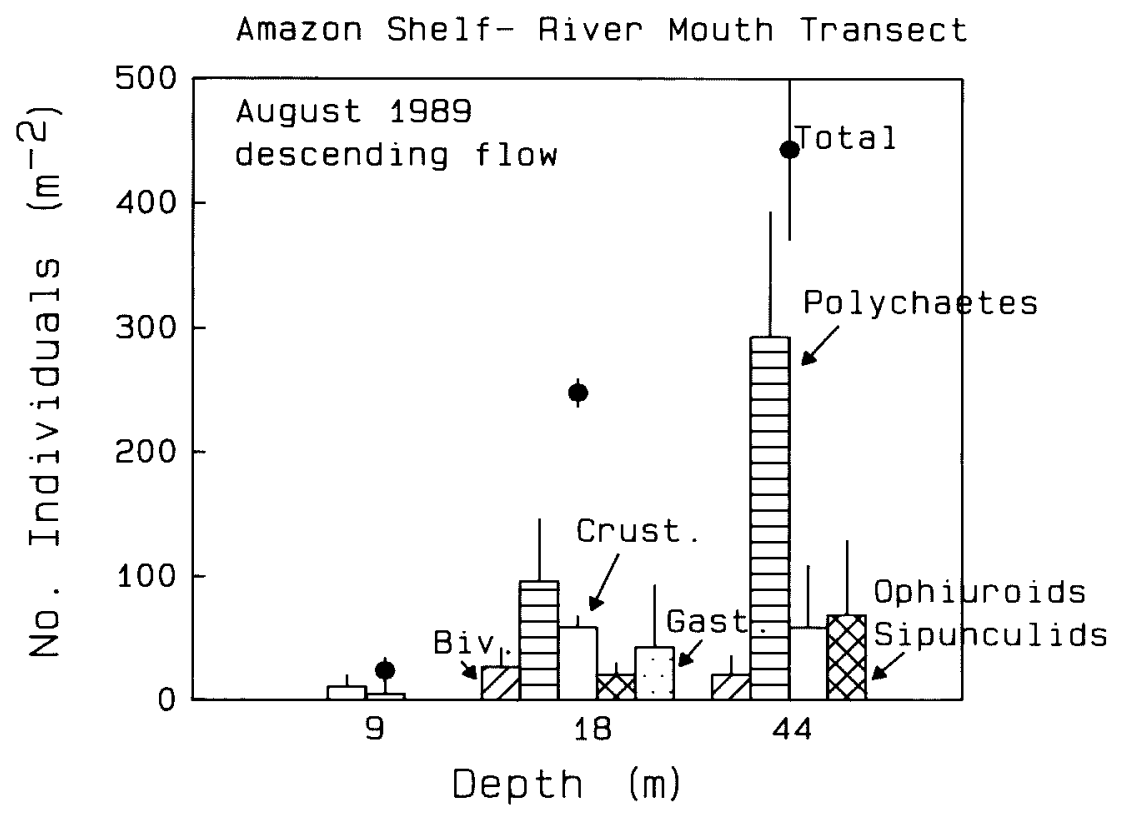

Fig. 6: Inshore-offshore patterns in macrobenthos along RMT during August 1989. (Biv., Crust., and Gast. refer to bivalves, crustaceans, and gastropods, respectively.) 
... no evidence of

sexually mature fauna

has been found as yet. addressed. There remain a variety of major unknowns regarding biogeochemical processes within Amazon Shelf deposits, including the timing and relative importance of physical and biological transport events in determining diagenetic properties at different locations. There are major classes of reactions occurring which deplete pore water $\mathrm{K}^{+}, \mathrm{Mg}^{++}, \mathrm{Ca}^{++}, \mathrm{Fe}^{++}, \mathrm{Mn}^{++}$and $\mathrm{Si}(\mathrm{OH})_{4}$, the characterization of which has only begun. Also, it is not clear how and when benthos are recruited or immigrate to this dynamic region, as no evidence of sexually mature fauna has been found as yet. Numerous new questions have arisen in addition to those originally posed. Some will be resolved by additional sampling of low river flow conditions (and lower wind stress), and by deeper sampling of sediment deposits using piston cores. In addition, completion of sample analyses and experiments from earlier cruises, modeling, and interdisciplinary information exchange should further constrain interpretations.

\section{Acknowledgements}

Numerous U.S. and Brazilian AmasSeds participants and the crew of the R/V ISELIN have helped provide the extensive logistical support required to carry out this project. We thank D. Guffy, S. Wirick, M. Green, D. Veidt, W. Rizzitello, H. Vigil, Q. Xia, R. Sievers, C. Sievers, W. Wallace, M. Montague, R. Cruz, P. Souza, and I. Carvalho for technical and field assistance. This research is funded by NSF grant OCE-8812907.

References

Aller, J.Y. and R.C. Aller, 1986: General characteristics of benthic faunas on the Amazon inner continental shelf with comparison to the shelf off the Changjiang River, East China Sea. Cont. Shelf Res., 6, 291-310.

Aller, R.C., J.E. Mackin and R.T. Cox, 1986: Diagenesis of $\mathrm{Fe}$ and $\mathrm{S}$ in Amazon inner shelf muds: apparent dominance of Fe reduction and implications for the genesis of ironstones. Cont. Shelf Res., 6, 263-289.

Berner, R.A., 1980: Early Diagenesis. Princeton Univ. Press, Princeton, NJ, 241 pp.

Chanton. J.P. and C.S. Martens. 1987: Biogeochemical cycling in an organic-rich coastal marine basin. 7 . Sulfur mass balance, oxygen uptake and sulfide retention. Geochim Cosmochim. Acta., 51, 1187-1199.

DeMaster, D.J., B.A. McKee, W.S. Moore, D.M. Nelson, W.J. Showers and W.O. Smith, 1991: Geochemical processes occurring in the waters at the Amazon River/Ocean Boundary. Oceanography, 4, 15-20.

Figueiredo, A.G., C.A. Nittrouer, J.M. Rine, and M.A.M. Silva, 1990: Stratigraphic evidence of environmental change during the late holocene on the Amazon Shelf. EOS, 71,1376 .

Geyer, W.R., R.C. Beardsley, J. Candela, B.M. Castro, R.V. Legeckis, S.J. Lentz, R. Limeburner, L.B. Miranda and J.H. Trowbridge, 1991: The physical oceanography of the Amazon outflow. Oceanography, 4, 8-14.

Hedges, J.I., W.A. Clark, P.D. Quay, J.E. Richey, A.H. Devol and U. de M. Santos. 1986: Compositions and fluxes of particulate organic material in the Amazon River. Limnol. Oceanogr., 31, 717-738.

Jorgensen, B.B., 1982: Mineralization of organic matter in the sea bed-the role of sulphate reduction. Nature, 296. 643-645.

Kineke, G.C., R.W. Sternberg, D.A. Cacchione, K. Kranck and D.E. Drake, 1991: Distribution and characteristics of suspended sediment on the Amazon Shelf. Oceanography, 4, 21-26.

Mackin, J.E. and K.T. Swider, 1989: Organic matter decomposition pathways and oxygen consumption in coastal marine sediments. Jour. Mar. Res., 47, 681-716.

, R.C. Aller and W.J. Ullman, 1988: The effects of iron reduction and nonsteady-state diagenesis on iodine, ammonium, and boron distributions in sediments from the Amazon continental shelf. Cont. Shelf Res., 8, 363386.

Meade, R.H., T. Dunne, J.E. Richey, U. de M. Santos and E. Salatil, 1985: Storage and remobilization of suspended sediment in the lower Amazon River of Brazil. Science, 228, 488-490.

Nittrouer, C.A., D.J. DeMaster, A.G. Figueiredo and J.M. Rine, 1991 a: An interdisciplinary investigation of a complex coastal environment. Oceanography, 4, 3-7.

S.A. Kuehl, J.M. Rine, A.G. Figueiredo, L.E.C. Faria, G.T.M. Dias, M.A.M. Silva, M.A. Allison, T.D. Pacioni, M.P. Segall, E.C. Underkoffler, H.V. Borges and O.F. Silveira, 1991b: Sedimentology and stratigraphy of the Amazon continental shelf. Oceanography, 4, 33-38.

Richey, J.E., J.I. Hedges, A.H. Devol, P.D. Quay, R. Victoria, L. Martinelli and B.R. Forsberg, 1990: Biogeochemistry of carbon in the Amazon River. Limnol. Oceanogr., $35,352-371$.

Showers, W.J. and D.G. Angle, 1986: Stable isotope characterization of organic accumulation on the Amazon Continental Shelf. Cont. Shelf Res., 6, 227-244. $\square$ 